\title{
The Global Impact of the Zika Virus Pandemic: The Importance of Emergency Preparedness
}

\author{
Annekathryn Goodman \\ Harvard Medical School, Department of Obstetrics and Gynecology, Massachusetts General Hospital, MGH Global Disaster \\ Response, Boston, MA, USA \\ Email: agoodman@mgh.harvard.edu
}

How to cite this paper: Goodman, A. (2020) The Global Impact of the Zika Virus Pandemic: The Importance of Emergency Preparedness. Health, 12, 132-140.

https://doi.org/10.4236/health.2020.122012

Received: January 20, 2020

Accepted: February 14, 2020

Published: February 17, 2020

Copyright (C 2020 by author(s) and Scientific Research Publishing Inc. This work is licensed under the Creative Commons Attribution International License (CC BY 4.0).

http://creativecommons.org/licenses/by/4.0/ cc (i) Open Access

\begin{abstract}
The 2015 outbreak of Zika virus in Brazil led to a significant increase of neonatal microcephaly. While Zika virus was identified in Africa in the 1940s and was noted to be present in Asia, it was not until 2007 that there was a significant shift in the behavior of the virus. Reasons for this change in Zika virus behavior and pathogenesis could be due to a change in the virulence of the virus, and a new ability to infect the human host. Additionally, the changing habitat of mosquitoes along with increasing urbanization and changes of human habitats has increased the risk of Zika virus exposure. This review summarizes the response to the Zika pandemic and recommendations for interventions through the lens of the Sendai Framework for disaster risk reduction. Emergency preparedness focuses on lessening the likelihood and the impact of disasters. Preparedness encompasses the actions of mitigation, prevention, response, and recovery.
\end{abstract}

\section{Keywords}

Zika Virus, Pandemic, Emergency Preparedness, Sendai Framework, Microcephaly, Aedes Mosquito, Microcephaly

\section{Background}

Zika virus is a mosquito-borne flavivirus that is closely related to the dengue and yellow fever viruses. However, the Zika virus, unlike other flaviviruses, crosses the placental barrier and causes active infection in the fetal brains, which results in malformations of the brain or fetal demise [1]. In May of 2015, the Pan American Health Organization issued an epidemiological alert with recommendations to detect and manage Zika virus infections [2]. By February 2016 given the precipitous spread of the virus across the Americas, the World Health Or- 
ganization declared Zika virus infection a public health emergency of international concern [3].

While Zika virus was first identified in 1947 in Africa, the first documented human outbreak with over 19,000 cases (an estimated 73\% of the population) was reported in 2007 in Yap Island, Micronesia [4]. Before the Yap Island outbreak, only fourteen human cases had been reported [5]. Zika was thought to be endemic in many countries of Asia [6]. In 2013-2014, French Polynesia experienced an outbreak with an estimated 32,000 cases. There have been multiple outbreaks in many Pacific island countries since then [7]. The most recent outbreak was first recorded in Brazil in 2015 and then spread to the Americas, Pacific Asia, and Africa. Laboratory-confirmed cases of Zika virus infections have now been identified in sixteen states in the United States [8]. Zika has been found in more than forty countries and territories [9].

In February 2015, a dengue-like outbreak occurred in the Northeastern regions of Brazil with symptoms of a rash, pruritus, low-grade fever, pain in joints and muscles and eye pain in an estimated 400,000 to 1.3 million suspected human cases [2]. In April, Zika virus was identified by reverse transcriptase polymerase chain reaction among the affected individuals. By September 2015, the Brazilian Ministry of Health reported an increased number of babies with microcephaly. Since this outbreak, epidemiologic and virologic investigations have led to a much fuller picture of the Zika virus infection.

Zika virus is spread via the bite of Aedes mosquitoes. It can also be spread sexually and by blood transfusions. The virus has been detected in blood, urine, semen, amniotic fluid, breast milk, and cerebrospinal fluid [10]. In adults, self-limited symptoms lasting an average of a week can be mild and include fever, red eyes, joint pain, and a rash. The occasional development of Guillain-Barré can occur. Guillain-Barré is an autoimmune disease that impacts the peripheral nervous system with symptoms that range from mild and brief episodes of weakness to devastating paralysis. Groups at higher risk for mosquito-borne illness are those living in crowded urban areas with standing pools of stagnant water and limited access to mosquito nets and insect repellents.

The most devastating outcome of Zika infection is the congenital malformations of babies born to women who were exposed to Zika during pregnancy. Recent studies have demonstrated that Zika virus directly infects human cortical neural progenitor cells and this causes reduced cell growth and dysregulation of transcription [11]. A recent analysis of outcomes showed that one in seven children from a Zika virus-infected pregnancy had a Zika-associated birth defect [12]. Brain development has a critical growth phase during the first three years of life [12]. Several Zika-associated birth defects include structural anomalies of brain or eyes present at birth and detected from birth to age two years (Table 1). These abnormalities lead to intellectual challenges, seizures, vision and hearing problems, difficulties with feeding, and slow development.

Testing blood, urine, or saliva for the presence of Zika virus RNA identifies and diagnoses the infection. As of 2019, there are currently two FDA-approved 
Table 1. Structural abnormalities of brain and eyes in Zika-affected infants (adapted from Rice et al., 2018 [12]).

\begin{tabular}{|c|c|c|c|}
\hline BRAIN & Definitions & Eye & Definitions \\
\hline Intra-cranial calcifications & & 1) Microphthalmia & 1) Abnormally small \\
\hline Cerebral atrophy & & 2) Anophthalmia & 2) Absence of one or both eyes \\
\hline Corpus Callosum abnormalities & & 3) Coloboma & $\begin{array}{l}\text { 3) Part of the eye does not } \\
\text { form due to failure of fusion }\end{array}$ \\
\hline \multirow[t]{3}{*}{ Cerebellar abnormalities } & & 4) Cataract & $\begin{array}{l}\text { of an embryonic feature } \\
\text { called intraocular fissure }\end{array}$ \\
\hline & & 5) Intraocular calcifications & \\
\hline & & & 4) Clouding of lens of the eye \\
\hline 1) Porencephaly & $\begin{array}{l}\text { 1) Cysts/cavities within } \\
\text { cerebral hemisphere }\end{array}$ & Chorioretinal anomalies & \\
\hline \multicolumn{4}{|l|}{ 2) Hydranencephaly } \\
\hline & 2) Fluid in brain & & \\
\hline \multicolumn{4}{|l|}{ 3) Ventriculomegaly } \\
\hline & 3) Dilated lateral ventricles & & \\
\hline Abnormal cortical formation: & $\begin{array}{l}\text { 1) Multiple small gyri (microgyri) } \\
\text { creating excessive folding of the brain }\end{array}$ & & \\
\hline 1) Polymicrogyria & leading to an abnormally thick cortex. & & \\
\hline 2) Lissencephaly & $\begin{array}{l}\text { 2) Smooth brain-caused by defective } \\
\text { neuronal migration during the } 12 \text { th to }\end{array}$ & & \\
\hline 3) Pachygyria & $\begin{array}{l}\text { 24th weeks of gestation resulting in a } \\
\text { lack of development of brain folds }\end{array}$ & & \\
\hline 4) Schizencephaly & (gyri) and grooves (sulci). & & \\
\hline \multirow[t]{2}{*}{ 5) Grey Matter heterotopia } & $\begin{array}{l}\text { 3) Abnormal migration of nerve cells } \\
\text { (neurons) in the developing brain and } \\
\text { nervous system: few gyri (the ridges } \\
\text { between the wrinkles in the brain), } \\
\text { and they are usually broad and flat. } \\
\text { 4) Abnormal slits or clefts } \\
\text { in the cerebral hemispheres }\end{array}$ & & \\
\hline & $\begin{array}{l}\text { 5) Clumps of gray matter } \\
\text { (nodules of neurons) located } \\
\text { in the wrong part of the brain. }\end{array}$ & & \\
\hline
\end{tabular}

tests for Zika virus antibodies [13].

This review summarizes the response to the Zika pandemic and recommendations for interventions through the lens of the Sendai Framework for disaster risk reduction [14]. Emergency preparedness focuses on lessening the likelihood and the impact of disasters. Preparedness encompasses the actions of mitigation, prevention, response, and recovery.

\section{Mitigation}

The Zika epidemic and its consequences outline the seriousness of this international public health threat. The mosquito-borne illness is in part perpetuated by the poverty and lack of infrastructure of particular human habitats around the world [15]. Prevention must involve mosquito control and also behavioral changes such as use of condoms and abstinence. Standard mosquito control 
measures include insect repellant, covering most of the body with long sleeve shirts, and pants, mosquito nets. Additionally it is important to remove standing water in houses and neighborhoods to reduce mosquito breeding grounds. Currently, there is no effective vaccine [10]. Both the Aedes Aegypti and Aedes Albopictus species of mosquito are believed to be the major mosquito species involved in urban Zika transmission [16]. These mosquitos are active during daylight hours thereby necessitating the need for the daytime measures of repellent use and clothing covering. The ultimate mitigation effort will be the development of a vaccine. Effective vector control measures and interventions require ongoing support and participation by local governments and ministries of health [17].

International mitigation efforts include managing climate change, and improving and overhauling crumbling infrastructure of hospitals and sanitation systems. This requires a deeper understanding of social and ecological risk factors. There has been a call to mobilize communities through public education campaigns through use of the whole community concept [15]. This requires community leadership, partnership, and development of emergency response system to contain epidemics. Another important mitigation effort involves the development of a robust surveillance system with reporting tools and the ability to trace people who have been exposed.

\section{Preparedness}

The Zika virus pandemic identified significant gaps in the public health system readiness and the need for sustained investments in the national public health emergency preparedness and response capacity [18]. The Zika viral infection has direct impact on the global burden of maternal-child disease. The World Health Organization has set up a Zika incident management team to survey and report on prevalence and incident of new outbreaks [7]. The European commission organized a new infectious disease consortium and plan for coordinated research and communication with twenty-five institutional partners in Europe, North America, Asia, Africa, and Latin America called ZikaPLAN [19]. This consortium brings experts in virology, entomology, arboviral disease, birth-defect surveillance, research, and communications together. One continued challenge to surveillance is the lack of universal availability of screening for Zika [15].

Preventive options are summarized in Table 2.

The 2015 Brazil epidemic is thought to have started in 2014 during an international sports event where people from Zika-endemic countries visited Brazil [17]. This highlights the importance of planning preparedness for contemporary transmittable illnesses during other international mass gatherings such as World Olympics and Paralymptic Games. Good surveillance of and communication about world epidemics, infectious outbreaks, and new febrile illnesses is mandatory. That information would allow the host nation to prepare for and mitigate against mosquito-borne illnesses and water/sanitation associated illnesses. 
Table 2. Preventive and control options for Zika virus infection (adapted from Tambo et al., 2016 [15]).

\begin{tabular}{ll}
\hline Interventions & Response \\
\hline Vaccine & No vaccine or drug currently available \\
\hline Education & Health Education \\
& Community and social mobilization \\
\hline Personal Interventions & Development of resilience culture \\
& Condom promotion \\
& Family Planning \\
& Abortion Access \\
\hline Insecticides & Improved hygiene and sanitation \\
\hline Household and Community Modifications & DEET \\
& Picardin \\
\hline
\end{tabular}

\section{Response}

Media attention was key in publicizing the story of the tragic neonatal outcomes from Zika in Brazil 2015 [17]. Public health responses are crucial and there have been successful responses between government and healthcare. One response led by New York City Health and hospitals involved a close collaboration between hospital systems and the New York City Department of Health [20]. The collaboration involved using the most up-to-date guidelines, laboratory support, and information sharing. This collaboration can be used as a model for other emerging infectious disease threats.

Center for Disease Control (CDC) published guidelines for the evaluation and management of infants with congenital Zika virus infection [21]. Standard evaluations of the neonate and child during well care visits are recommended. Laboratory testing for Zika virus is recommended for infants born to mothers with laboratory evidence of Zika virus infection during pregnancy. Additional testing should include a cranial ultrasound and comprehensive ophthalmologic evaluation by age one month to identify possible subclinical brain and eye findings. Currently only $68 \%$ of children with Zika abnormalities in the US and Territories received follow-up care [12]. Lack of follow-up followed the crises of displacement of families in Puerto Rico and US Virgin Islands due to the hurricanes of 2017 [22]. Careful follow-up is recommended for early referral to interventional services. The follow-up period should be during the first two years of life.

In the setting of a new outbreak of Zika, pregnant women who have traveled or live in affected areas should be tested. Male partners who have been exposed 
to Zika should use condoms [2]. Women of reproductive age who have been exposed should not get pregnant until they are in the convalescent period after infection. Another consideration during an outbreak is the possibility of transmission through blood transfusions [8]. Blood donors should be screened for Zika in regions impacted by an outbreak [11]. Overall most Zika infections are self-limited.

\section{Recovery}

Zika virus infections have been identified in communities where high rates of concurrent neurologic conditions such as microcephaly and Guillain-Barré syndrome were occurring. The Zika pandemic is unlike other public health emergencies as the consequences of this infectious disease pandemic impact future generations with congenital malformations (including microcephaly) [23]. The current pandemic has been controlled with the last proven case of Zika spread in the continental United States reported in 2017 [24]. Those infants who experience severe neurologic consequences will need life-long care and intervention. This healthcare needs cause significant financial burdens on the affected families. Funding for support and intervention must come from governments [25].

There are currently no clinically approved interventions such as vaccines for the Zika virus infection. Best supportive care during the illness is the mainstay of therapy. As Zika virus can occur concomitantly with other flaviviruses such as Dengue, aspirin and nonsteroidal anti-inflammatory agent, which can exacerbate hemolysis, should be avoided [2].

\section{Lessons Learned}

While Zika virus was identified in Africa in the 1940s and was noted to be present in Asia, it was not until 2007 that there was a significant shift in the behavior of the virus. This change in Zika virus behavior and pathogenesis could either be due to a change in the virulence of the virus and/or a new ability to infect the human host. Another possibility is that human habitation has changed the environment enough to introduce this mosquito-borne illness into man-made environments. In 1992, the Institute of Medicine identified and named a new category of global threat: emerging infections thought to be either secondary to new habitats and geographic areas or due to changes in the characteristics of the infectious agent such as virulence or antimicrobial resistance [26]. There has been a resurgence of many arboviruses such as West Nile virus, Dengue, and Chikungunya. Factors implicated in this resurgence include: genetic changes to the virus, climate change, uncontrolled use of insecticides, expansion of the geographic distribution of mosquitos, adaptation to new hosts, global human population growth, extensive urbanization, lack of effective mosquito control, and increased international travel [27] [28]. Zika virus falls into this category of a resurgent vector-borne illness.

The most recent chapter of the Zika story involves the vertical transmission of 
virus to human fetus with devastating consequences. This recent story spans 2015 through 2017, a time of increasing climate change and subsequent destructive storm systems in the Americas. The second lesson learned is that destruction and displacement of human populations after natural disasters puts them at higher risk for infectious diseases including mosquito-borne illnesses. A third lesson is the new recommended intervention of changing individual behavior including sexual protective measures or abstinence to avoid vector-borne disease [17]. Finally, collaboration and communication across disciplines and countries are crucial as infectious diseases threaten to become pandemics leading to the crucial need for a robust surveillance system. The response to the Zika pandemic has led to the development of better infrastructure to support effective collaborations both nationally and internationally.

\section{Conflicts of Interest}

The author declares no conflicts of interest regarding the publication of this paper.

\section{References}

[1] Sirohi, D. and Kuhn, R.J. (2017) Zika Virus Structure, Maturation, and Receptors. The Journal of Infectious Diseases, 216, S935-S944. https://doi.org/10.1093/infdis/jix515

[2] Vest, K.G. (2016) Zika Virus: A Basic Overview of an Emerging Arboviral Infection in the Western Hemisphere. Disaster Medicine Public Health Preparedness, 10, 707-712. https://doi.org/10.1017/dmp.2016.43

[3] WHO (2016) Director-General Summarizes the Outcome of the Emergency Committee Regarding Clusters of Microcephaly and Guillain-Barré Syndrome. World Health Organization, Geneva. http://www.who.int/mediacentre/news/statements/2016/emergency-committee-zika -microcephaly/en

[4] Duffy, M.R., Chen, T.H., Hancock, W.T., et al. (2009) Zika Virus Outbreak on Yap Island, Federated States of Micronesia. New England Journal of Medicine, 360, 2536-2543. https://doi.org/10.1056/NEJMoa0805715

[5] Faye, O., Freire, C.C.M., Iamarino, A., et al. (2014) Molecular Evolution of Zika Virus during Its Emergence in the 20th Century. PLoS Neglected Tropical Diseases, 8, e2636. https://doi.org/10.1371/journal.pntd.0002636

[6] Duong, V., Dussart, P. and Buchy, P. (2017) Zika Virus in Asia. International Journal of Infectious Diseases, 54, 121-128. https://doi.org/10.1016/j.ijid.2016.11.420

[7] Squires, R.C., Konings, F. and World Health Organization Regional Office for the Western Pacific Zika Incident Management Team (2016) Preparedness for Zika Virus Testing in the World Health Organization Western Pacific Region. Western Pacific Surveillance and Response Journal, 7, 44-47. https://doi.org/10.5365/wpsar.2016.7.1.007

[8] Plourde, A.R. and Bloch, E.M. (2016) A Literature Review of Zika Virus. Emerging Infectious Diseases, 22, 1185-1192. https://doi.org/10.3201/eid2207.151990

[9] Basarab, M., Bowman, C., Aarons, E.J. and Cropley, I. (2016) Zika Virus. BMJ, 352, i1049. https://doi.org/10.1136/bmj.i1049 
[10] Pierson, T.C. and Graham, B.S. (2016) Zika Virus: Immunity and Vaccine Development. Cell, 167, 625-631. https://doi.org/10.1016/j.cell.2016.09.020

[11] White, M.K., Wollebo, H.S., David Beckham, J., Tyler, K.L. and Khalili, K. (2016) Zika Virus: An Emergent Neuropathological Agent. Annals of Neurology, 80, 479-489. https://doi.org/10.1002/ana.24748

[12] Rice, M.E., Galang, R.R., Roth, N.M., Ellington, S.R., Moore, C.A., Valencia-Prado, M., Ellis, E.M., Honein, M., et al. (2018) Vital Signs: Zika-Associated Birth Defects and Neurodevelopmental Abnormalities Possibly Associated with Congenital Zika Virus Infection-U.S. Territories and Freely Associated States, 2018. MMWR Morbidity Mortality Weekly Report, 67, 858-867. https://doi.org/10.15585/mmwr.mm6731e1

[13] FDA U.S. Food \& Drug Administration (2019) Zika Virus Response Updates from FDA.

https://www.fda.gov/emergency-preparedness-and-response/mcm-issues/zika-virus -response-updates-fda

[14] Aitsi-Selmi, A., Egawa, S., Sasaki, H., et al. (2015) The Sendai Framework for Disaster Risk Reduction: Renewing the Global Commitment to People's Resilience, Health, and Well-Being. The International Journal of Disaster Risk Science, 6, 164-176. https://doi.org/10.1007/s13753-015-0050-9

[15] Tambo, E., Chuisseu, P.D., Ngogang, J.Y. and Khater, E.I. (2016) Deciphering Emerging Zika and Dengue Viral Epidemics: Implications for Global Maternal-Child Health Burden. Journal of Infection Public Health, 9, 240-250. https://doi.org/10.1016/j.jiph.2016.02.005

[16] Song, B.H., Yun, S.I., Woolley, M. and Lee, Y.M. (2017) Zika Virus: History, Epidemiology, Transmission, and Clinical Presentation. Journal of Neuroimmunology, 308, 50-64. https://doi.org/10.1016/j.jneuroim.2017.03.001

[17] Singer, L., Vest, K.G. and Beadling, C.W. (2017) Zika Virus: A Review of Management Considerations and Controversies at Six Months. Disaster Medicine Public Health Preparedness, 11, 279-284. https://doi.org/10.1017/dmp.2016.141

[18] Duchin, J.S. (2016) US Public Health Preparedness for Zika and Other Threats Remains Vulnerable. Disaster Medicine Public Health Preparedness, 10, 298-299. https://doi.org/10.1017/dmp.2016.26

[19] Wilder-Smith, A., Preet, R., Renhorn, K.E., et al. (2017) Zika Plan: Zika Preparedness Latin American Network. Global Health Action, 10, Article ID: 1398485. https://doi.org/10.1080/16549716.2017.1398485

[20] Madad, S., Tate, A., Rand, M., et al. (2018) Zika Virus Preparedness and Response Efforts through the Collaboration between a Health Care Delivery System and a Local Public Health Department. Disaster Medicine Public Health Preparedness, 12, 689-691. https://doi.org/10.1017/dmp.2018.5

[21] Adebanjo, T., Godfred-Cato, S., Viens, L., et al. (2017) Update: Interim Guidance for the Diagnosis, Evaluation, and Management of Infants with Possible Congenital Zika Virus Infection-United States, October 2017. MMWR Morbidity Mortality Weekly Report, 66, 1089-1099. https://doi.org/10.15585/mmwr.mm6641a1

[22] Kishore, N., Marqués, D., Mahmud, A., et al. (2018) Mortality in Puerto Rico after Hurricane Maria. New England Journal of Medicine, 379, 162-170. https://doi.org/10.1056/NEJMsa1803972

[23] McNeil, C.J. and Shetty, A.K. (2017) Zika Virus: A Serious Global Health Threat. Journal of Tropical Pediatrics, 63, 242-248. https://doi.org/10.1093/tropej/fmw080

[24] CDC Centers for Disease Control and Prevention (2019) Zika Virus: 2019 Case 
Counts in the US. https://www.cdc.gov/zika/reporting/2019-case-counts.html

[25] McCarthy, M. (2016) US Health Officials Press Congress for Zika Funds. BMJ, 352, i1545. https://doi.org/10.1136/bmj.i1545

[26] Institute of Medicine (US) Committee on Emerging Microbial Threats to Health, Lederberg, J., Shope, R.E. and Oaks, S.C. (1992) Emerging Infections: Microbial Threats to Health in the United States. National Academy Press, Washington DC.

[27] Musso, D. and Gubler, D.J. (2016) Zika Virus. Clinical Microbiology Reviews, 29, 487-524. https://doi.org/10.1128/CMR.00072-15

[28] Chen, L.H. and Hamer, D.H. (2016) Ideas and Opinions. Zika Virus: Rapid Spread in the Western Hemisphere. Annals of Internal Medicine, 164, 613-615.

https://doi.org/10.7326/M16-0150 